\title{
Risk factors for developing subdural hematoma: a registry-based study in 1457 patients with shunted idiopathic normal pressure hydrocephalus
}

\author{
Johan Gasslander, MD, ${ }^{1,2}$ Nina Sundström, PhD, MsEP, ${ }^{3}$ Anders Eklund, PhD, MsEP, ${ }^{3}$ \\ Lars-Owe D. Koskinen, PhD, MD, ${ }^{1}$ and Jan Malm, PhD, MD1
}

\begin{abstract}
'Department of Pharmacology and Clinical Neuroscience, Umeå University, Umeå; '2Departments of Cardiology and Health, Medicine and Caring Services, Linkoping University, Vrinnevi General Hospital Norrköping; and ${ }^{3}$ Department of Radiation Sciences, Umeå University, Umeå, Sweden
\end{abstract}

\begin{abstract}
OBJECTIVE Subdural hematomas and hygromas (SDHs) are common complications in idiopathic normal pressure hydrocephalus (iNPH) patients with shunts. In this registry-based study, patients with shunted iNPH were screened nationwide to identify perioperative variables that may increase the risk of SDH.
\end{abstract}

METHODS The Swedish Hydrocephalus Quality Registry was reviewed for iNPH patients who had undergone shunt surgery in Sweden in 2004-2014. Potential risk factors for SDH were recorded preoperatively and 3 months after surgery. Drug prescriptions were identified from a national pharmacy database. Patients who developed SDHs were compared with those without SDHs.

RESULTS The study population consisted of 1457 patients, $152(10.4 \%)$ of whom developed an SDH. Men developed an SDH more often than women (OR 2.084, 95\% Cl 1.421-3.058, $p<0.001)$. Patients on platelet aggregation inhibitors developed an SDH more often than those who were not $(\mathrm{OR} 1.733,95 \% \mathrm{Cl} 1.236-2.431, \mathrm{p}=0.001)$. At surgery, shunt opening pressures had been set $5.9 \mathrm{~mm} \mathrm{H}_{2} \mathrm{O}$ lower in the SDH group than in the no-SDH group (109.6 \pm 24.1 vs $115.5 \pm$ $25.4 \mathrm{~mm} \mathrm{H}_{2} \mathrm{O}$, respectively, $\mathrm{p}=0.009$ ). Antisiphoning devices (ASDs) were used in 892 patients but did not prevent SDH. Mean opening pressures at surgery and the follow-up were lower with shunts with an ASD, without causing more SDHs. No other differences were seen between the groups.

CONCLUSIONS iNPH patients in this study were diagnosed and operated on in routine practice; thus, the results represent everyday care. Male sex, antiplatelet medication, and a lower opening pressure at surgery were risk factors for SDH. Physical status and comorbidity were not. ASD did not prevent SDH, but a shunt with an ASD allowed a lower opening pressure without causing more SDHs.

https://thejns.org/doi/abs/10.3171/2019.10.JNS191223

KEYWORDS hydrocephalus; normal pressure; hygroma; chronic subdural hematoma; cerebrospinal shunt; complications

$I^{3}$ DIOPATHIC normal pressure hydrocephalus (iNPH) is a syndrome characterized by a triad of symptoms: gait disturbance, urinary incontinence, and cognitive impairment. ${ }^{11}$ Cerebrospinal fluid (CSF) shunt surgery is the standard treatment for iNPH, and about $60 \%-80 \%$ of shunt patients are improved 1 year postoperatively. ${ }^{6,26}$ However, complications do occur, with revision rates as high as $13 \% .{ }^{26}$ The most common complications are subdural hematomas and hygromas (SDHs), ${ }^{4}$ with a reported incidence of $2 \%-17 \%$. 3,6,18,22,25,26,28 Previous studies on this subject have been small, hospital-based, and often retro- spective. . $^{3,13,24}$ Thus, there is a need for a large prospective study to identify possible risk factors for developing SDH in order to reduce future complications and provide new ideas for future shunt designs.

An SDH is caused by a rupture of the bridging veins in the subdural space. ${ }^{17}$ In shunt patients, it is believed to be triggered by overdrainage of $\mathrm{CSF}^{23}$ with a secondary reduction of intracranial pressure, when a patient goes from the supine to the sitting or standing position. ${ }^{19}$ The risk of overdrainage and SDH can be increased by having a low opening pressure of the shunt. ${ }^{4,5}$ However, the

ABBREVIATIONS ASD = antisiphoning device; $C S F$ = cerebrospinal fluid; $\mathrm{NPH}$ = idiopathic normal pressure hydrocephalus; NSAID = nonsteroidal anti-inflammatory drug; SDH = subdural hematoma/hygroma; SHQR = Swedish Hydrocephalus Quality Registry; SPDR = Swedish Prescribed Drug Register.

SUBMITTED May 1, 2019. ACCEPTED October 29, 2019.

INCLUDE WHEN CITING Published online January 10, 2020; DOI: 10.3171/2019.10.JNS191223. 
postoperative opening pressure must be individualized, as the optimal opening pressure varies between patients and some patients may have greater improvement with a lower opening pressure. ${ }^{4,5}$

Other proposed risk factors for SDH after shunting include antiplatelet therapy (e.g., aspirin or clopidogrel) ${ }^{3}$ and an elevated BMI. ${ }^{13}$ A longer surgical procedure and female sex have been related to an increased risk for overdrainage. ${ }^{20}$ The use of shunts without antisiphoning devices (ASDs) has been proposed as a risk factor for overdrainage ${ }^{22}$ and $\mathrm{SDH} .{ }^{24}$ However, the conclusions are inconsistent. ${ }^{22}$ Different ASD mechanisms have also been compared in terms of overdrainage. ${ }^{10}$ It has been suggested that improvements in surgical technique and modern shunt technology have rendered fewer SDHs over the years, ${ }^{26}$ but the impact of shunt design and the use of ASDs still needs to be addressed in a larger study.

In 2004, the Swedish Hydrocephalus Quality Registry (SHQR) was started. In this registry, all patients operated on for hydrocephalus are prospectively recorded together with information from regular clinical follow-ups including shunt adjustments, complications, and revisions. For Swedish citizens, all drug prescriptions are also automatically registered in the Swedish Prescribed Drug Register (SPDR). In the present study, we investigated which perioperative variables contribute to an increased risk for $\mathrm{SDH}$ in patients with shunted iNPH.

\section{Methods}

In summary, all patients with shunted iNPH in Sweden who had been registered in the SHQR during the 10-year period 2004-2014 were included in this analysis. Patients who had developed an SDH postoperatively (SDH group) were compared with those without SDH (no-SDH group) to identify potential risk factors for developing SDH. Strengthening the Reporting of Observational Studies in Epidemiology (STROBE) guidelines were used in this study.

The ethics board at the University Hospital of Umeå approved all aspects of the study. When patients agree to undergo surgery, they are informed about their inclusion in the registry, and exclusion is always allowed.

\section{The Swedish Hydrocephalus Quality Registry}

The purpose of the SHQR is to improve hydrocephalus patient care by studying the epidemiology, clinical outcome, and complications of shunt surgery. Between 2004 and 2012, the registry covered five of the six neurosurgical units in Sweden, corresponding to about $80 \%$ of the Swedish population. In 2013 the sixth center was also included. At each center, preoperative, perioperative, and postoperative parameters are registered for patients (age $\geq 18$ years) who undergo hydrocephalus surgery.

If an SDH occurred, it had to be assessed and treated by one of the six Swedish neurosurgical units, as there were no other facilities performing neurosurgery in Sweden. Shunt complications throughout the study period were continuously reported to the registry. To validate the reliability of the SHQR data, centers were initially evaluated at external inspections in which the original data saved in the registry were manually cross-checked with the corresponding patient's medical records.

\section{Patients}

Patients suspected of having iNPH are examined at dedicated hydrocephalus centers, and the diagnosis is based on patient history, neurological examination, and MRI (or CT if MRI is contraindicated) that indicates communicating hydrocephalus. ${ }^{18}$ In Sweden, predictive tests such as the CSF tap test and/or infusion test are most often performed to aid in the decision of whether or not to insert a shunt. Prior to surgery, antiplatelet medication is discontinued according to recommendations by the clinical pharmacologist for that specific drug and is restarted 14-30 days after surgery. A follow-up at about 3 months after surgery includes a CT or MRI study and clinical evaluation.

Patients diagnosed with iNPH were included in the present study if they had been operated on for placement of a CSF shunt and registered as "iNPH" in the SHQR between January 1, 2004, and September 24, 2014. The following baseline parameters were obtained from the SHQR: age, sex, shunt type (adjustable or fixed), shunt system, ASD, proximal/distal catheter location, elective or acute surgery, opening pressure at shunt insertion and at the most recent follow-up, diabetes mellitus, hypertension, heart disease, previous stroke, and dates for occurring events. Gait score (Supplemental Table 1), balance score (Supplemental Table 1), Mini-Mental State Examination (MMSE) score, ${ }^{9}$ American Society of Anesthesiologists (ASA) physical status class, ${ }^{1}$ and modified Rankin Scale score $^{8,21,27}$ were noted in the SHQR at baseline before surgery and at the follow-up visit about 3 months after surgery.

\section{The Swedish Prescribed Drug Register}

In the SPDR, prescribed drugs are automatically registered for all citizens. Patients registered in the SHQR were cross-checked against the SPDR for prescriptions of anticoagulants (i.e., warfarin, novel oral anticoagulants), platelet aggregation inhibitors (i.e., acetylsalicylic acid, clopidogrel, ticagrelor, etc.), and nonsteroidal antiinflammatory drugs (NSAIDs; i.e., ibuprofen, diclofenac, naproxen, etc.) during any time in the study period. If any of these drugs were prescribed, they were paused preoperatively and then continued after the surgery.

\section{Shunt Systems}

Registered shunt systems in the SHQR were Strata, Delta (Medtronic Inc.), Codman Hakim programmable valve, Codman Hakim programmable valve with $\mathrm{Si}$ phonGuard, Codman Certas programmable valve, and Codman Hakim precision fixed pressure valve (Codman Neuro). Opening pressures were recalculated to $\mathrm{mm} \mathrm{H}_{2} \mathrm{O}$ for conformity. This was performed for Strata, Certas, and Delta. ${ }^{7,16}$ The Codman Hakim programmable valve (with and without SiphonGuard) was already calibrated in $\mathrm{mm}$ $\mathrm{H}_{2} \mathrm{O}$. Unfortunately, the Codman Hakim fixed pressure valve could not be converted to $\mathrm{mm}_{2} \mathrm{O}$ in an accurate way because of converting issues. In the SHQR, there are 


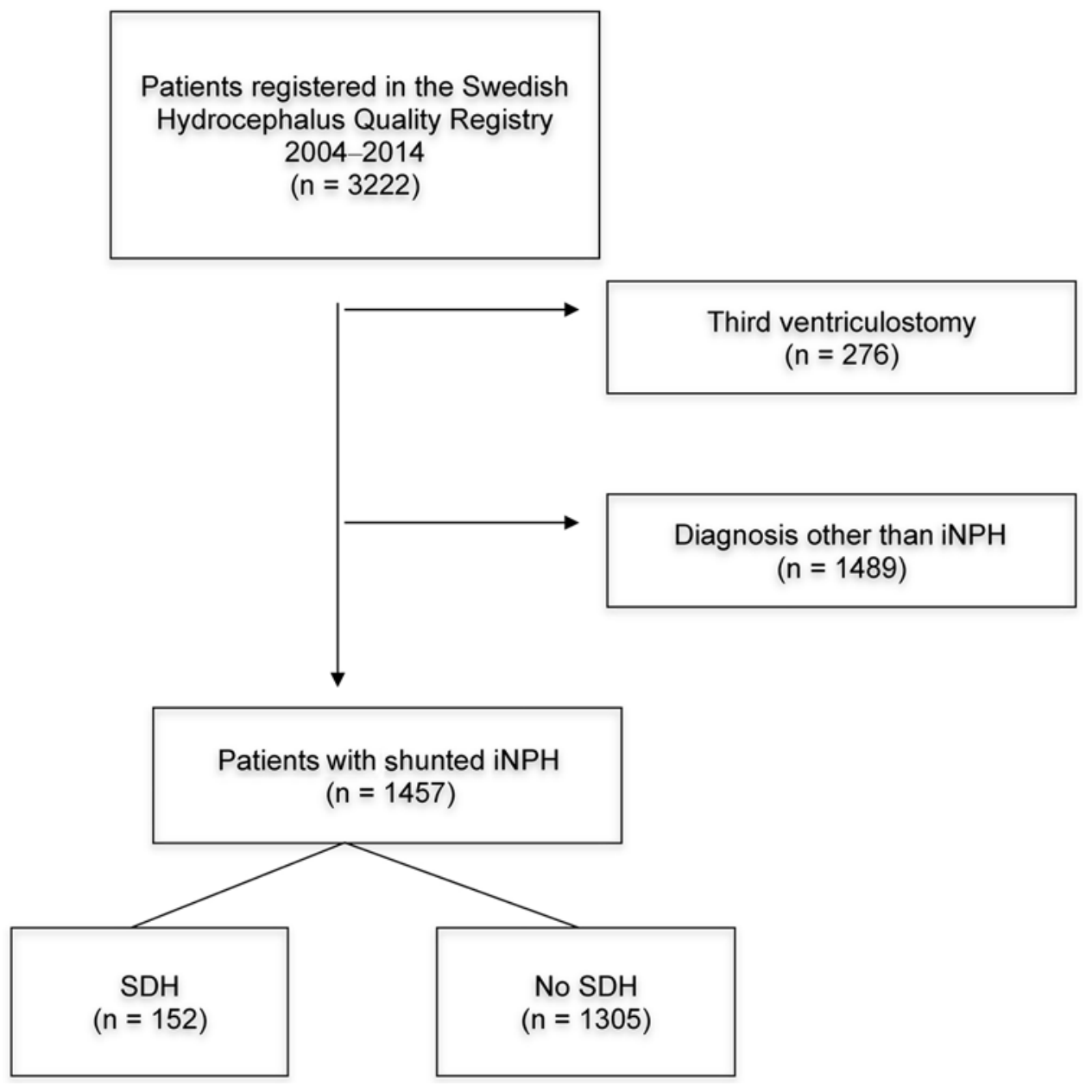

FIG. 1. Study flowchart for patient inclusion.

three settings for these valves, but in the Codman product brochure there are five settings. This made the conversion potentially inaccurate; therefore, these valves were excluded from the opening pressure analysis $(n=136)$.

\section{Statistical Analysis}

Statistical analyses were performed with IBM SPSS Statistics 23 (IBM Corp.). Ordinal and continuous variables were analyzed for distributional assumptions with a Shapiro-Wilk test. For continuous variables, mean values and standard deviations were calculated. For ordinal variables, medians and ranges or interquartile ranges were presented. Depending on the type of variable, a Pearson chi-square test, independent samples t-test, or MannWhitney U-test was used for comparisons. Significance was set at $\alpha=0.05$ (two-sided). We also performed a Bonferroni correction to avoid the problem of multiple testing of variables.

\section{Results}

A study flowchart with inclusions and exclusions is illustrated in Fig. 1. The final study population consisted of 1457 patients. Ninety percent of the patients had adjust- able ventriculoperitoneal shunts. In 152 (10.4\%) patients, a first-ever SDH was observed (SDH group) during the study period. The median time between shunt surgery and SDH was 158 days. Baseline characteristics of the study population are shown in Table 1, and Fig. 2 shows cumulative survival from shunt surgery to SDH. For the patients having an SDH, 9.9\% were conservatively treated (no treatment), 56.6\% were treated with opening pressure adjustment, and $33.6 \%$ underwent surgery.

Table 2 shows perioperative variables for iNPH patients with versus those without SDH. SDH was more common in men than women. In the SDH group, $75.0 \%$ of patients were men; in the no-SDH group, only $59.0 \%$ of patients were men (OR 2.084, 95\% CI 1.421-3.058, p < 0.001). The opening pressure at shunt insertion was slightly lower in the SDH group than the no-SDH group (109.6 vs 115.5 $\mathrm{mm} \mathrm{H}_{2} \mathrm{O}, \mathrm{p}=0.009$ ). After surgery and during the followup period, the most recent postoperative adjustment (before the SDH diagnosis in the SDH group and the most recent adjustment overall for the no-SDH group) was compared, and there were no differences in the opening pressure (SDH group $104.2 \mathrm{~mm} \mathrm{H}_{2} \mathrm{O}$ vs no-SDH group 106.9 $\mathrm{mm} \mathrm{H}_{2} \mathrm{O}, \mathrm{p}=0.43$ ).

The proportion of patients having a shunt with or with- 
TABLE 1. Baseline characteristics among patients with shunted iNPH

\begin{tabular}{|c|c|c|c|}
\hline Variable & Total & Male & Female \\
\hline No. of patients (\%) & 1457 & $884(60.7)$ & $573(39.3)$ \\
\hline Mean age in yrs (SD) & $72.75(7.82)$ & $72.91(7.48)$ & $72.50(8.31)$ \\
\hline \multicolumn{4}{|l|}{ SDH, no. (\%) } \\
\hline Yes & $152(10.4)$ & $114(12.9)$ & $38(6.6)$ \\
\hline No & $1305(89.6)$ & $770(87.1)$ & $535(93.4)$ \\
\hline Median time to SDH in days (IQR) & $158.0(52.6)$ & $124.5(50.6)$ & $238(63.6)$ \\
\hline \multicolumn{4}{|l|}{ Valve type, no. $(\%)^{*}$} \\
\hline Adjustable & $1303(89.6)$ & $803(90.8)$ & $500(87.6)$ \\
\hline Strata & $821(56.4)$ & $495(56.0)$ & $326(57.1)$ \\
\hline Codman & $402(27.6)$ & $262(29.6)$ & $140(24.5)$ \\
\hline Codman w/ ASD & $58(4.0)$ & $35(4.0)$ & $23(4.0)$ \\
\hline Certas & $18(1.2)$ & $9(1.0)$ & $9(1.6)$ \\
\hline Model unknown & $4(0.3)$ & $2(0.2)$ & $2(0.4)$ \\
\hline Fixed pressure & $152(10.4)$ & $81(9.2)$ & $71(12.4)$ \\
\hline Delta & $13(0.9)$ & $8(0.9)$ & $5(0.9)$ \\
\hline Hakim & $136(9.3)$ & $72(8.2)$ & $64(11.3)$ \\
\hline Model unknown & $3(0.2)$ & $1(0.1)$ & $2(0.4)$ \\
\hline \multicolumn{4}{|l|}{ ASD, no. $(\%)^{*}$} \\
\hline Yes & $892(62.7)$ & $538(62.0)$ & $354(63.8)$ \\
\hline No & $531(37.3)$ & $330(38.0)$ & $201(36.2)$ \\
\hline Mean opening pressure at surgery in $\mathrm{mm}_{2} \mathrm{O}$ (SD) & $114.9(25.4)$ & $116.6(26.6)$ & $112.2(23.0)$ \\
\hline Mean opening pressure last known in $\mathrm{mm}_{2} \mathrm{O}$ (SD) & $106.6(31.1)$ & $109.0(32.9)$ & $102.8(27.8)$ \\
\hline Mean gait score presurgery (range) & $4.39(1-8)$ & $4.28(1-8)$ & $4.56(1-8)$ \\
\hline Mean gait score 3 mos (range) & $3.70(1-8)$ & $3.58(1-8)$ & $3.89(1-8)$ \\
\hline Mean balance score presurgery (range) & $3.77(1-7)$ & $3.70(1-7)$ & $3.89(1-7)$ \\
\hline Mean balance score 3 mos (range) & $3.31(1-7)$ & $3.29(1-7)$ & $3.36(1-7)$ \\
\hline Mean mRS score presurgery (range)† & $2.63(0-5)$ & $2.62(0-5)$ & $2.65(1-5)$ \\
\hline Mean mRS score 3 mos (range) $\dagger$ & $2.28(0-5)$ & $2.25(0-5)$ & $2.34(0-5)$ \\
\hline Mean MMSE score presurgery (SD) & $23.68(4.96)$ & $23.61(4.97)$ & $23.79(4.94)$ \\
\hline Mean MMSE score 3 mos (SD) & $24.82(4.84)$ & $24.58(4.98)$ & $25.21(4.60)$ \\
\hline Mean ASA class (range) & $2.36(1-4)$ & $2.4(1-4)$ & $2.30(1-4)$ \\
\hline \multicolumn{4}{|l|}{ Diabetes mellitus, no. $(\%)^{*}$} \\
\hline Yes & $323(25.2)$ & $213(27.8)$ & $110(21.3)$ \\
\hline No & $960(74.8)$ & $553(72.2)$ & $407(78.7)$ \\
\hline \multicolumn{4}{|l|}{ Hypertension, no. (\%)* } \\
\hline Yes & $708(54.1)$ & $446(57.1)$ & $262(49.7)$ \\
\hline No & $600(45.9)$ & $335(42.9)$ & $265(50.3)$ \\
\hline \multicolumn{4}{|l|}{ Heart disease, no. (\%)* } \\
\hline Yes & $373(29.0)$ & $267(34.8)$ & $106(20.4)$ \\
\hline No & $914(71.0)$ & $501(65.2)$ & $413(79.6)$ \\
\hline \multicolumn{4}{|l|}{ Previous stroke, no. $(\%)^{*}$} \\
\hline Yes & $179(14.3)$ & $136(18.3)$ & $43(8.5)$ \\
\hline No & $1070(85.7)$ & $606(81.7)$ & $464(91.5)$ \\
\hline \multicolumn{4}{|l|}{ Planned surgery, no. $(\%)^{*}$} \\
\hline Yes & $1414(97.7)$ & $861(98.0)$ & $553(97.2)$ \\
\hline No & $34(2.3)$ & $18(2.0)$ & $16(2.8)$ \\
\hline
\end{tabular}


» CONTINUED FROM PAGE 671

TABLE 1. Baseline characteristics among patients with shunted iNPH

\begin{tabular}{|c|c|c|c|}
\hline Variable & Total & Male & Female \\
\hline \multicolumn{4}{|c|}{ Proximal catheter location, no. $(\%)^{*}$} \\
\hline Frontal & $1424(98.4)$ & $864(98.4)$ & $560(98.4)$ \\
\hline Occipital & $22(1.5)$ & $13(1.5)$ & $9(1.6)$ \\
\hline Bilat & $1(0.1)$ & $1(0.1)$ & $0(0)$ \\
\hline \multicolumn{4}{|l|}{ Anticoagulant, no. (\%) } \\
\hline Yes & $149(10.2)$ & $86(9.7)$ & $63(11.0)$ \\
\hline No & $1308(89.8)$ & $798(90.3)$ & $510(89.0)$ \\
\hline \multicolumn{4}{|l|}{ PAI, no. (\%) } \\
\hline Yes & $518(35.6)$ & $324(36.7)$ & $194(33.9)$ \\
\hline No & $939(64.4)$ & $560(63.3)$ & $379(66.1)$ \\
\hline \multicolumn{4}{|l|}{ NSAID, no. (\%) } \\
\hline Yes & $141(9.7)$ & $74(8.4)$ & $67(11.7)$ \\
\hline No & $1316(90.3)$ & $810(91.6)$ & $506(88.3)$ \\
\hline \multicolumn{4}{|l|}{ Anticoagulant + PAl, no. (\%) } \\
\hline Yes & $56(3.8)$ & $33(3.7)$ & $23(4.0)$ \\
\hline No & $1401(96.2)$ & $851(96.3)$ & $550(96.0)$ \\
\hline \multicolumn{4}{|l|}{ Anticoagulant + NSAID, no. (\%) } \\
\hline Yes & $13(0.9)$ & $5(0.6)$ & $8(1.4)$ \\
\hline No & $1444(99.1)$ & $879(99.4)$ & $565(98.6)$ \\
\hline \multicolumn{4}{|l|}{ PAI + NSAID, no. (\%) } \\
\hline Yes & $67(4.6)$ & $37(4.2)$ & $30(5.2)$ \\
\hline No & $1390(95.4)$ & $847(95.8)$ & $543(94.8)$ \\
\hline \multicolumn{4}{|c|}{ Anticoagulant + PAI + NSAID, no. (\%) } \\
\hline Yes & $13(0.9)$ & $9(1.0)$ & $4(0.7)$ \\
\hline No & $1444(99.1)$ & $875(99.0)$ & $569(99.3)$ \\
\hline
\end{tabular}

out an ASD was the same in the SDH and no-SDH groups. However, in the group with ASDs, the mean opening pressure at the time of surgery was $25.6 \mathrm{~mm} \mathrm{H}_{2} \mathrm{O}$ lower than in the group without ASDs (106.7 vs $132.3 \mathrm{~mm} \mathrm{H}_{2} \mathrm{O}$, p < 0.001 ). The mean opening pressure at the most recent adjustment is shown in Fig. 3, and it was $28.0 \mathrm{~mm} \mathrm{H}_{2} \mathrm{O}$ lower in the group with ASDs than in the group without (97.3 vs $125.3 \mathrm{~mm} \mathrm{H}_{2} \mathrm{O}$, respectively, $\mathrm{p}<0.001$ ).

In the SDH group, $47.4 \%$ of the patients were treated with antiplatelet drugs, compared to $34.2 \%$ in the no-SDH group (OR 1.733, 95\% CI 1.236-2.431, $\mathrm{p}=0.001)$. For anticoagulants, a similar trend was observed, but the difference between the two groups was not significant $(14.5 \%$ SDH group vs $9.7 \%$ no-SDH group, OR $0.637,95 \%$ CI $0.391-1.037, \mathrm{p}=0.07)$. No other variables were significantly different (Table 2).

A Bonferroni correction was also performed to avoid the problem of multiple testing of variables. After this, patient sex and antiplatelet drugs were still significant. With this stricter $\alpha$ level, however, shunt opening pressure was only close to significant.

\section{Discussion}

In this large nationwide study, iNPH patients were diagnosed and operated on in routine practice; thus, the results represent everyday care. Male sex, use of antiplatelet drugs, and a lower opening pressure at surgery were associated with an increased frequency of SDH. An ASD did not protect patients from an SDH. However, ASD shunts had a mean opening pressure that was at least $25 \mathrm{~mm} \mathrm{H}_{2} \mathrm{O}$ lower than in the shunts without an ASD both at shunt insertion and at the most recent adjustment. Comorbidity and preoperative physical state did not matter in the development of an SDH. About one-tenth of the iNPH patients developed an SDH, which is in line with previous studies. ${ }^{3,6,18,22,28}$

The present results are similar to those of a recent, smaller study in which shunts with ASD did not prevent $\mathrm{SDH} .{ }^{22}$ However, in the present study, the opening pressure was significantly lower in the patients who had shunts with ASD. These findings suggest that a shunt with an ASD may allow a lower opening pressure than a shunt without an ASD. Considerable investments have been made in devices for preventing $\mathrm{SDH}$, and since an ASD is included 


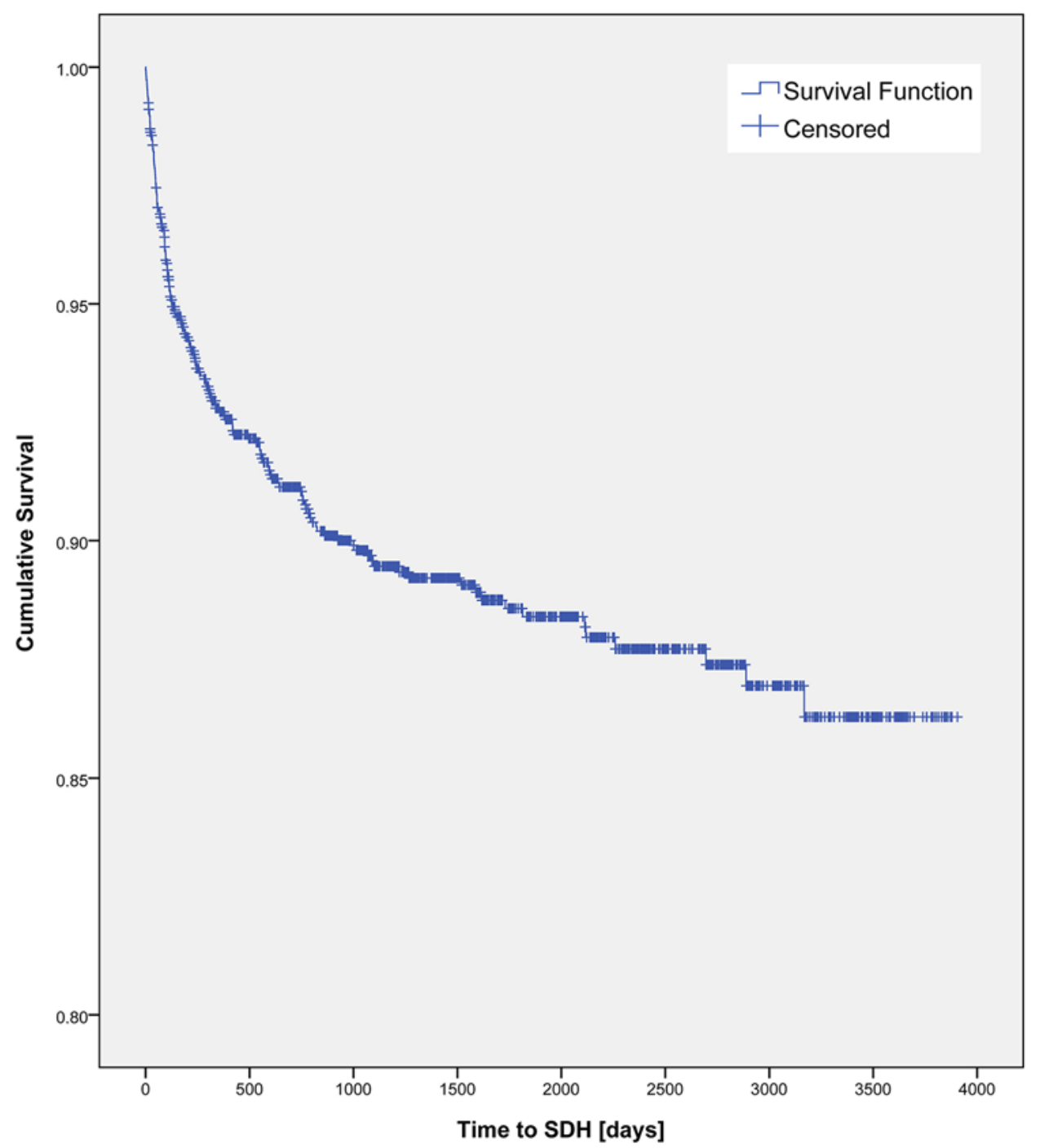

FIG. 2. Kaplan-Meier graph showing cumulative survival from the time of shunt surgery to SDH. Within 60 days after shunt surgery, 43 (3.0\%) patients had an SDH (likely symptomatic), and between 60 and 120 days after surgery, 27 (1.9\%) patients had an $\mathrm{SDH}$ (likely asymptomatic, found at the routine 3 -month follow-up). Figure is available in color online only.

in most new shunt systems, it is interesting that an ASD did not reduce the occurrence of SDH. However, a lower opening pressure is expected to lead to a better clinical outcome than a medium or higher opening pressure, ${ }^{4}$ but a lower opening pressure also increases the risk of SDHs., ${ }^{4,5}$ Our study indicates that surgeons could utilize this opportunity to individualize and optimize the opening pressure downward in order to improve outcome for the individual without increasing the risk of causing an SDH.

In Sweden, adjustable shunts with an ASD are the most commonly used CSF shunts. In the present study, no differences among models, between fixed and adjustable valves, or among proximal catheter locations were seen. However, only $152(10.4 \%)$ shunts had a fixed pressure setting. Different companies have different ASD designs, and we tested only two of them. The SVASONA study (Shunt Valves Plus Shunt Assistant Versus Shunt Valves Alone for Controlling Overdrainage in Idiopathic Normal Pressure Hydrocepha- lus in Adults) tested a third design - gravitational valve versus nongravitational-and there the relative risk of symptomatic SDH was reduced by $90 \% .^{14}$ This finding is interesting but must be confirmed in head-to-head comparisons among the three ASD constructions on the market.

Lower opening pressures at shunt insertion, compared to higher opening pressures, were associated with more SDHs; however, the difference was small. We could not find a distinct threshold below which the risk of SDH increased. According to previous studies, when it comes to developing $\mathrm{SDH}$, it does not seem to matter if the opening pressure is low right after surgery or if it starts out high and is gradually reduced..$^{22}$ In the present study, the opening pressure at the most recent adjustment was not significantly lower in the SDH group, and this was mainly attributable to a larger opening pressure reduction in those without SDH.

More men than women presented with an SDH, which 
TABLE 2. Comparisons between patients with and without SDH

\begin{tabular}{|c|c|c|c|c|c|}
\hline Variable & $\mathrm{SDH}$ & No SDH & $\begin{array}{c}p \\
\text { Value }\end{array}$ & $\begin{array}{l}\text { No. of Cases of SDH, } \\
\text { No SDH in Analysis }\end{array}$ & OR $(95 \% \mathrm{Cl})$ \\
\hline Sex: F/M (\%) & $25.0 / 75.0$ & $41.0 / 59.0$ & $<0.001$ & 152,1305 & $2.084(1.421-3.058)$ \\
\hline Mean age in yrs (SD) & $71.8(7.98)$ & $72.9(7.80)$ & 0.18 & 152,1305 & \\
\hline Adjustable valve (\%) & 90.1 & 89.5 & 0.81 & 152,1303 & $1.073(0.612-1.882)$ \\
\hline $\begin{array}{l}\text { Valve model: Strata/Codman/ } \\
\text { Codman w/ ASD/Hakim/ } \\
\text { Certas/Delta (\%) }\end{array}$ & 53.6/28.5/7.3/8.6/0.7/1.3 & $57.1 / 27.7 / 3.6 / 9.5 / 1.3 / 0.8$ & 0.33 & 151,1297 & \\
\hline ASD (\%) & 62.7 & 62.7 & $>0.99$ & 150,1273 & $0.999(0.704-1.418)$ \\
\hline $\begin{array}{l}\text { Mean opening pressure at } \\
\text { surgery in } \mathrm{mm} \mathrm{H}_{2} \mathrm{O}(\mathrm{SD})\end{array}$ & $109.6(24.1)$ & $115.5(25.4)$ & 0.009 & 130,1139 & \\
\hline $\begin{array}{l}\text { Mean opening pressure at last } \\
\text { adjustment in } \mathrm{mm} \mathrm{H}_{2} \mathrm{O}(\mathrm{SD})\end{array}$ & $104.2(36.4)$ & $106.9(30.5)$ & 0.43 & 134,1181 & \\
\hline $\begin{array}{l}\text { Median gait score presurgery } \\
\text { (range) }\end{array}$ & $4(1-8)$ & $4(1-8)$ & 0.32 & 141,1151 & \\
\hline $\begin{array}{l}\text { Median gait score } 3 \text { mos post- } \\
\text { surgery (range) }\end{array}$ & $3(1-8)$ & $3(1-8)$ & 0.28 & 111,1014 & \\
\hline $\begin{array}{l}\text { Median balance score presur- } \\
\text { gery (range) }\end{array}$ & $3(1-7)$ & $3(1-7)$ & 0.71 & 124,1037 & \\
\hline $\begin{array}{l}\text { Median balance score } 3 \text { mos } \\
\text { postsurgery (range) }\end{array}$ & $3(1-7)$ & $3(1-7)$ & 0.75 & 102,945 & \\
\hline $\begin{array}{l}\text { Median mRS score presurgery } \\
\quad \text { (range) }\end{array}$ & $2(0-5)$ & $3(0-5)$ & 0.97 & 117,1047 & \\
\hline $\begin{array}{l}\text { Median mRS score } 3 \text { mos } \\
\text { postsurgery (range) }\end{array}$ & $2(0-5)$ & $2(0-5)$ & 0.67 & 96,968 & \\
\hline $\begin{array}{l}\text { Median MMSE score presurgery } \\
\quad \text { (range) }\end{array}$ & $24(7-30)$ & $25(0-30)$ & 0.10 & 125,1030 & \\
\hline $\begin{array}{l}\text { Median MMSE score } 3 \text { mos } \\
\text { postsurgery (range) }\end{array}$ & $26(8-30)$ & $26(3-30)$ & 0.28 & 102,890 & \\
\hline Median ASA class (range) & $2(1-4)$ & $2(1-4)$ & 0.54 & 136,1172 & \\
\hline Diabetes mellitus (\%) & 29.7 & 24.6 & 0.19 & 138,1145 & $1.294(0.877-1.909)$ \\
\hline Hypertension (\%) & 55.1 & 54.0 & 0.81 & 138,1170 & $1.043(0.732-1.488)$ \\
\hline Heart disease (\%) & 34.1 & 28.4 & 0.16 & 138,1149 & $1.304(0.896-1.897)$ \\
\hline Previous stroke (\%) & 14.3 & 14.3 & 0.99 & 133,1116 & $0.996(0.596-1.665)$ \\
\hline Planned surgery (\%) & 98.7 & 97.5 & 0.38 & 151,1297 & $1.885(0.447-7.943)$ \\
\hline $\begin{array}{l}\text { Proximal catheter location: } \\
\text { frontal/occipital/bilat (\%) }\end{array}$ & $98.0 / 2.0 / 0.0$ & $98.5 / 1.5 / 0.1$ & 0.55 & 152,1295 & \\
\hline Anticoagulant (\%) & 14.5 & 9.7 & 0.07 & 152,1305 & $0.637(0.391-1.037)$ \\
\hline PAI (\%) & 47.4 & 34.2 & 0.001 & 152,1305 & $1.733(1.236-2.431$ \\
\hline NSAID (\%) & 11.2 & 9.5 & 0.51 & 152,1305 & $1.199(0.701-2.052)$ \\
\hline Anticoagulant + PAI (\%) & 5.9 & 3.6 & 0.16 & 152,1305 & $1.685(0.809-3.509)$ \\
\hline Anticoagulant + NSAID (\%) & 0.7 & 0.9 & 0.75 & 152,1305 & $0.714(0.092-5.526)$ \\
\hline PAI + NSAID (\%) & 5.9 & 4.4 & 0.41 & 152,1305 & $1.353(0.657-2.789)$ \\
\hline Anticoagulant + PAI + NSAID (\%) & 2.0 & 0.8 & 0.13 & 152,1305 & $2.607(0.710-9.580)$ \\
\hline
\end{tabular}

is contrary to findings in the SVASONA study. ${ }^{20}$ However, that study mixed SDH with other symptoms of overdrainage such as headache, included only about one-tenth as many patients as in our study, and was a hospital-based study. Our finding that men are at greater risk could be attributable to lifestyle factors since men are overrepresented when it comes to stroke and intracerebral hemor- rhage. ${ }^{2}$ The mean age of iNPH patients is about 70 years, and iNPH patients have more cardiovascular risk factors than the healthy population. ${ }^{12}$ Thus, men's greater cardiovascular risk factors and lifestyle factors could be reasons why male iNPH patients are more at risk of developing SDHs than females. Another reason could be that as a group, men are taller than women. This could lead 


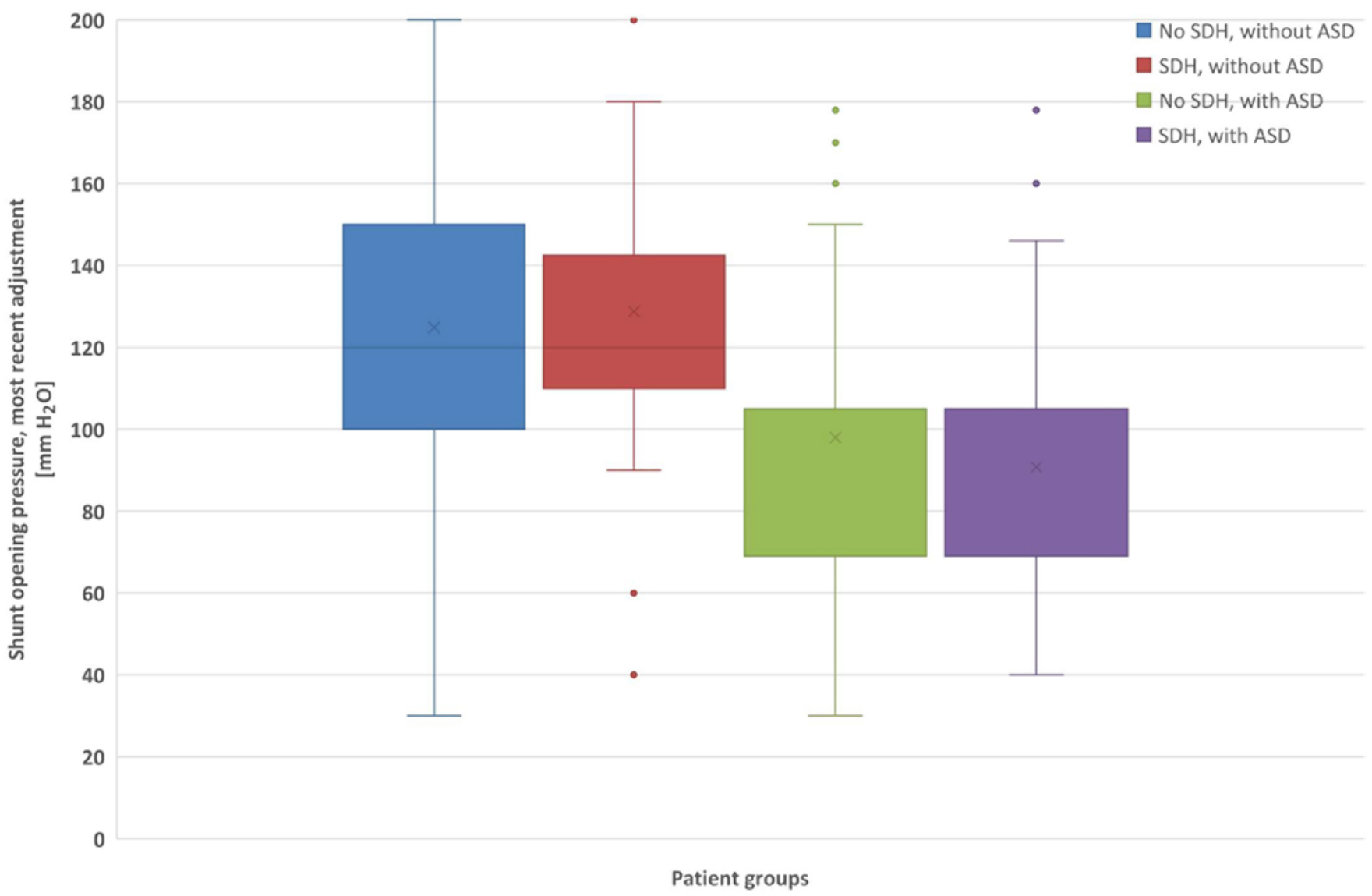

FIG. 3. Box plot displaying shunt opening pressure at the most recent adjustment for patients without SDH/without $A S D$ ( $n=475$, blue), with SDH/without ASD ( $n=56$, red), without SDH/with ASD $(n=798$, green), and with SDH/with ASD ( $n=94$, purple). Lines indicating median values coincide with the upper box delimiter for the green and purple groups. Figure is available in color online only.

to greater hydrostatic pressure on the shunt valve, which could facilitate overdrainage and SDH.

Platelet aggregation inhibitors were more commonly used in the SDH group, which was expected. ${ }^{3,15} \mathrm{We}$ observed a similar finding for anticoagulants, but the difference between the two groups was not significant. At the time of this study, novel oral anticoagulants had been recently introduced onto the market, and in the future, it is important to investigate the risk with these more and more commonly used drugs in shunt patients. The use of NSAIDs did not affect the development of SDH. Only 141 (9.7\%) patients had prescriptions for NSAIDs. In Sweden, however, NSAIDs are often distributed over the counter, which makes it more difficult to know which patients use these drugs.

Not comorbidity, not preoperative physical status, nor functional independence increased the risk for developing SDH. These findings indicate that the frailty of the patient does not matter for SDH.

\section{Study Strengths and Limitations}

The primary strengths of this study are the large cohort of patients with shunted iNPH and the prospective design, both of which support the reliability of the results. The data on all the SDH patients in this study have been crossvalidated with medical records for verification of the SDH. SDHs are typically discovered only at checkups or when they are symptomatic; thus, it is likely that the true incidence of SDH is even higher given undiagnosed asymptomatic cases. However, it is also likely that these cases are less important because of their asymptomatic nature. A limitation of this study is that chronic subdural hematoma and hygroma are grouped together as a single entity. Because of the clinical and radiological similarity between them, the SHQR has chosen to not separate them, and we followed suit. The study was limited to the variables listed in the SHQR; therefore, we could not access the size of the SDHs or test some other interesting variables (e.g., BMI, height, weight).

\section{Conclusions}

The present study is the largest on risk factors for developing SDH after shunt surgery in iNPH patients. Male sex, antiplatelet drugs, and a lower shunt opening pressure at the time of surgery were risk factors for SDH. Comorbidity and the physical state of the patient were not. The risk factors identified are not straightforwardly translat- 
able into clinical recommendations to reduce the number of SDHs in the future. However, although the use of an ASD did not protect against SDH, it did allow for a lower opening pressure with a sustained level of SDH complications. Thus, the use of an ASD is recommended to achieve an optimized clinical outcome.

\section{Acknowledgments}

For their continuous and meticulous work in registering every surgically treated hydrocephalus patient in the SHQR over the years, all registrars and clinicians at each participating center are gratefully acknowledged.

\section{References}

1. American Society of Anesthesiologists: ASA Physical Status Classification System Relative Value Guide. Schaumburg, IL: ASA, 2019

2. Appelros P, Stegmayr B, Terént A: Sex differences in stroke epidemiology: a systematic review. Stroke 40:1082-1090, 2009

3. Birkeland P, Lauritsen J, Poulsen FR: Aspirin is associated with an increased risk of subdural hematoma in normalpressure hydrocephalus patients following shunt implantation. J Neurosurg 123:423-426, 2015

4. Boon AJ, Tans JT, Delwel EJ, Egeler-Peerdeman SM, Hanlo PW, Wurzer HA, et al: Dutch Normal-Pressure Hydrocephalus Study: randomized comparison of low- and medium-pressure shunts. J Neurosurg 88:490-495, 1998

5. Delwel EJ, de Jong DA, Dammers R, Kurt E, van den Brink W, Dirven CM: A randomised trial of high and low pressure level settings on an adjustable ventriculoperitoneal shunt valve for idiopathic normal pressure hydrocephalus: results of the Dutch evaluation programme Strata shunt (DEPSS) trial. J Neurol Neurosurg Psychiatry 84:813-817, 2013

6. Eide PK, Sorteberg W: Diagnostic intracranial pressure monitoring and surgical management in idiopathic normal pressure hydrocephalus: a 6-year review of 214 patients. Neurosurgery 66:80-91, 2010

7. Eklund A, Koskinen LO, Williams MA, Luciano MG, Dombrowski SM, Malm J: Hydrodynamics of the Certas ${ }^{\mathrm{TM}}$ programmable valve for the treatment of hydrocephalus. Fluids Barriers CNS 9:12, 2012

8. Farrell B, Godwin J, Richards S, Warlow C: The United Kingdom transient ischaemic attack (UK-TIA) aspirin trial: final results. J Neurol Neurosurg Psychiatry 54:1044-1054, 1991

9. Folstein MF, Folstein SE, McHugh PR: "Mini-mental state". A practical method for grading the cognitive state of patients for the clinician. J Psychiatr Res 12:189-198, 1975

10. Gehlen M, Eklund A, Kurtcuoglu V, Malm J, Schmid Daners M: Comparison of anti-siphon devices-how do they affect CSF dynamics in supine and upright posture? Acta Neurochir (Wien) 159:1389-1397, 2017

11. Hakim S, Adams RD: The special clinical problem of symptomatic hydrocephalus with normal cerebrospinal fluid pressure. Observations on cerebrospinal fluid hydrodynamics. J Neurol Sci 2:307-327, 1965

12. Israelsson H, Carlberg B, Wikkelsö C, Laurell K, Kahlon B, Leijon G, et al: Vascular risk factors in INPH: a prospective case-control study (the INPH-CRasH study). Neurology 88:577-585, 2017

13. Khan QU, Wharen RE, Grewal SS, Thomas CS, Deen HG Jr, Reimer R, et al: Overdrainage shunt complications in idiopathic normal-pressure hydrocephalus and lumbar puncture opening pressure. J Neurosurg 119:1498-1502, 2013

14. Lemcke J, Meier U, Müller C, Fritsch MJ, Kehler U, Langer
$\mathrm{N}$, et al: Safety and efficacy of gravitational shunt valves in patients with idiopathic normal pressure hydrocephalus: a pragmatic, randomised, open label, multicentre trial (SVASONA). J Neurol Neurosurg Psychiatry 84:850-857, 2013

15. Lindvall P, Koskinen LO: Anticoagulants and antiplatelet agents and the risk of development and recurrence of chronic subdural haematomas. J Clin Neurosci 16:1287-1290, 2009

16. Lundkvist B, Eklund A, Koskinen LO, Malm J: An adjustable CSF shunt: advices for clinical use. Acta Neurol Scand 108:38-42, 2003

17. Markwalder TM: Chronic subdural hematomas: a review. J Neurosurg 54:637-645, 1981

18. Marmarou A, Black P, Bergsneider M, Klinge P, Relkin N: Guidelines for management of idiopathic normal pressure hydrocephalus: progress to date. Acta Neurochir Suppl 95:237-240, 2005

19. McCullough DC, Fox JL: Negative intracranial pressure hydrocephalus in adults with shunts and its relationship to the production of subdural hematoma. J Neurosurg 40:372-375, 1974

20. Meier U, Stengel D, Müller C, Fritsch MJ, Kehler U, Langer $\mathrm{N}$, et al: Predictors of subsequent overdrainage and clinical outcomes after ventriculoperitoneal shunting for idiopathic normal pressure hydrocephalus. Neurosurgery 73:10541060, 2013

21. Rankin J: Cerebral vascular accidents in patients over the age of 60. II. Prognosis. Scott Med J 2:200-215, 1957

22. Sæhle T, Farahmand D, Eide PK, Tisell M, Wikkelsö C: A randomized controlled dual-center trial on shunt complications in idiopathic normal-pressure hydrocephalus treated with gradually reduced or "fixed" pressure valve settings. J Neurosurg 121:1257-1263, 2014

23. Samuelson S, Long DM, Chou SN: Subdural hematoma as a complication of shunting procedures for normal pressure hydrocephalus. J Neurosurg 37:548-551, 1972

24. Sprung C, Miethke C, Shakeri K, Lanksch WR: The importance of the dual-switch valve for the treatment of adult normotensive or hypertensive hydrocephalus. Eur J Pediatr Surg 7 (Suppl 1):38-40, 1997 (Erratum in Eur J Pediatr Surg 8:64, 1998)

25. Sundström N, Lagebrant M, Eklund A, Koskinen LD, Malm J: Subdural hematomas in 1846 patients with shunted idiopathic normal pressure hydrocephalus: treatment and long-term survival. J Neurosurg 129:797-804, 2018

26. Toma AK, Papadopoulos MC, Stapleton S, Kitchen ND, Watkins LD: Systematic review of the outcome of shunt surgery in idiopathic normal-pressure hydrocephalus. Acta Neurochir (Wien) 155:1977-1980, 2013

27. van Swieten JC, Koudstaal PJ, Visser MC, Schouten HJ, van Gijn J: Interobserver agreement for the assessment of handicap in stroke patients. Stroke 19:604-607, 1988

28. Zemack G, Romner B: Adjustable valves in normal-pressure hydrocephalus: a retrospective study of 218 patients. Neurosurgery 51:1392-1402, 2002

\section{Disclosures}

The authors report no conflict of interest concerning the materials or methods used in this study or the findings specified in this paper.

\section{Author Contributions}

Conception and design: Sundström, Malm. Acquisition of data: Gasslander, Sundström. Analysis and interpretation of data: all authors. Drafting the article: Gasslander, Sundström, Malm. Critically revising the article: all authors. Reviewed submitted version of manuscript: all authors. Approved the final version of the manuscript on behalf of all authors: Gasslander. Statistical analysis: 
Gasslander, Sundström, Eklund. Administrative/technical/material support: Malm. Study supervision: Malm.

\section{Supplemental Information}

Online-Only Content

Supplemental material is available with the online version of the article.

Supplemental Table 1. https://thejns.org/doi/suppl/10.3171/ 2019.10.JNS191223.

\section{Previous Presentations}

Part of this material was presented as an oral presentation at the 7th Annual Meeting of the International Society for Hydrocephalus and Cerebrospinal Fluid Disorders held in Banff, Alberta, Canada, on September 18-21, 2015.

\section{Correspondence}

Johan Gasslander: Vrinnevi General Hospital, Norrköping, Sweden.johangasslander89@gmail.com. 